


\section{About IJMA [last updated October, $\left.1^{\text {st }}, 2021\right]$}

$\checkmark$ International Journal of Medical Arts is the Official Journal of the Damietta Faculty of Medicine, AlAzhar University, Egypt

$\checkmark$ It is an International, Open Access, Double-blind, Peer-reviewed Journal

$\checkmark$ Published four times a year

$\checkmark$ The First Issue was published in July 2019

$\checkmark$ Published under the following license: Creative Commons Attribution-ShareAlike 4.0 International Public License (CC BY-SA 4.0). It had updated from the Creative Commons license [CC BY] in volume 2, Issue 4, October 2020 About IJMA

$\checkmark$ The Egyptian Knowledge Bank hosts the web site of IJMA

$\checkmark$ The Egyptian Knowledge Bank supports IJMA

$\checkmark$ IJMA follows the regulations of the International Committee of Medical Journal Editors

$\checkmark$ IJMA is indexed in the "Directory of Open Access Journals" [15 January 2021].

$\checkmark$ IJMA is indexed in J-Gate [29-6-2021]

$\checkmark$ IJMA is a member of the International Society of Managing and Technical Editors

$\checkmark$ Listed in "Index Copernicus", "Publons", "Academic resource index [ResearchBib]" "Electronics journal library", "Eurasian Scientific Journal Index", "WorldCat" Superstar Journal Database, and "Citefactor"

$\checkmark$ IJMA introduced to the search engine [BASE] through DOAJ

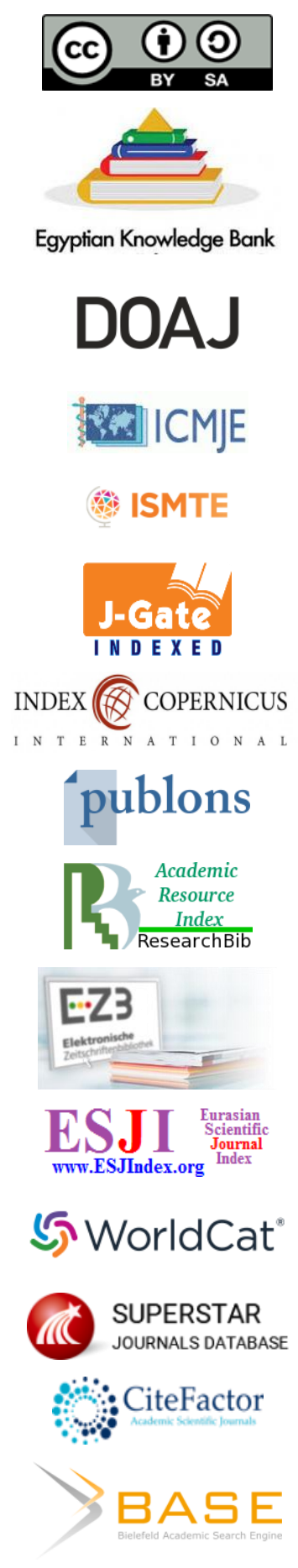




Available online at Journal Website
https://ijma.journals.ekb.eg/
Main subject [Neurosurgery]

Original Article

\title{
Comparative Study between Microscopic and Endoscopic Endonasal Trans-Sphenoidal Surgeries for Nonfunctioning Pituitary Macro-Adenomas
}

\author{
Mohammed El sebaee Abdel-Fattah [1], Mohammed Hossam Eldein Abu Shahba [2], Mohammed Shaban Ali Hassan \\ ${ }^{[2]}$, Hatem Mohammed Elsamouly ${ }^{[2]}$
}

1 Department of Neurosurgery, Damanhur National institute, Egypt

2 Department of Neurosurgery, Damietta Faculty of Medicine, Al-Azhar University, Egypt

Corresponding author: Mohammed El sebaee Abdel-Fattah

Email: dr.msebaee@domazhermedicine.edu.eg

Submission date: July 02, 2021; Acceptance date: November 07, 2021

DOI: $10.21608 / / J M A .2021 .83666 .1335$

DOAJ

\section{ABSTRACT}

Background: The transsphenoidal surgery has emerged as the standard treatment of pituitary adenomas. The endonasal transsphenoidal approach either microscopic or endoscopic affords a rhinological recovery with fewer sinonasal complaints.

Aim of the work: Comparison between microscopic and endoscopic endonasal trans-sphenoidal approaches in nonfunctioning pituitary adenomas.

Patients and Methods: Thirty patients with nonfunctioning pituitary adenomas were included from March 2015 to October 2020. The patients were subdivided into two groups, Group [A]: 15 patients for an endoscopic endonasal transsphenoidal approach, and Group [B]: 15 patients for microscopic endonasal transsphenoidal approach. All patients were subjected to history taking, general and neurological examination, visual, rhinological, endocrine and radiological assessment. All patients were followed up and examined by an attending neurosurgeon, otolaryngologist and endocrinologist one and three months and then yearly thereafter. The data were obtained and recorded. Complete tumor resection was the primary outcome. Other secondary outcomes included operative data and postoperative complications.

Results: Operative time ranged from 60.0 - 150.0 minutes [mean 108.0 and 88.0 minutes in groups $A$ and $B$ respectively]. Complete tumor resection achieved in 13 patients [86.7\%] of group A compared to 10 patients [66.7\%] in group $B$. Subtotal tumor resection achieved for 2 patients [13.3\%] and 3 patients [20\%] of groups A and B, respectively. Partial resection and insufficient removal was reported in one patient [6.7\%] for each in group $B$.

Conclusion: The endoscopic endonasal approach provides more favorable tumor removal, and hence was associated improved visual field and acuity, less postoperative pain and shorter hospitalization.

Keywords: Non-functioning Pituitary Tumors; Microscopic; Endoscopic; Endonasal; Transsphenoidal

This is an open-access article registered under the Creative Commons, ShareAlike 4.0 International license [CC BY-SA 4.0] [https://creativecommons.org/licenses/by-sa/4.0/legalcode.

Citation: Abdel-Fattah ME, Abu Shahba MH, Hassan MSA, Elsamouly HM. Comparative Study between Microscopic and Endoscopic Endonasal Trans-Sphenoidal Surgeries for Nonfunctioning Pituitary Macro-Adenomas. IJMA 2021; 3 [4] October-December: 1941-1946. [DOI: 10.21608/IJMA.2021.83666.1335].

* Main subject and any subcategories have been classified according to the research topic 


\section{INTRODUCTION}

Nonfunctioning pituitary adenomas account for approximately $30 \%$ of all pituitary adenomas and due to their lack of clinically detectable hormonal activity they tend to present with mass effects such as headache, visual field deficits, cranial nerve defects, or rarely cavernous sinus syndrome. If there is extensive tissue destruction, hypopituitarism results and expresses clinically. The nonfunctional pituitary tumors are not associated with clinical or biochemical evidence of hormone hypersecretion. Apoplexy is rare in nonfunctional pituitary adenomas; it can occur in all adenoma subtypes but is more common in nonfunctioning pituitary adenomas, with intra-tumor hemorrhage, which represents a medical emergency ${ }^{[1]}$.

The diagnosis of non-functioning pituitary tumors is achieved by both clinical and radiological tools. Computerized tomography [CT] scan and Magnetic Resonance Imaging [MRI] play an important role in the established of a final diagnosis. MRI with contrast is useful to define the precise size and extension of the tumors, evaluate vascular relationships, and detect any invasion of the surrounding structures. Also, it is important to detect the post-operative residual or recurrent tumor. CT scan of the paranasal sinuses is a very important tool before surgery ${ }^{[2]}$

The development of transsphenoidal approaches to the sella, was a major progress in the pituitary surgery. It permits resection of more than $95 \%$ of tumors using variations of this technique. The endonasal transsphenoidal approach either microscopic or endoscopic has many advantages over sublabial or transseptal techniques. It avoids the risks associated with other approaches [e.g., nasoseptal perforations, synechiae, upper lib numbness, anosmia and septal abscess [3]. However, the superiority of one approach over the other [endoscopic versus microscopic] is not well-established yet, especially in our institution due to recent introduction of endoscopic surgery.

\section{AIM OF THE WORK}

The aim of this work is to compare the clinical and radiological outcome between microscopic and endoscopic endonasal trans-sphenoidal approaches in nonfunctioning pituitary tumors.

\section{PATIENTS AND METHODS}

A prospective study was conducted on 30 patients with nonfunctioning pituitary tumors from March 2015 to October 2020, at neurosurgery department in Damietta University Hospital and Damanhur national institute The patients were subdivided randomly into two equal groups [closed envelope method], unless specific intervention is indicated for specific patient. Here, a shift to the indicated approach was made, and the patient was excluded from the study.

The groups were Group $[\mathrm{A}]$ for an endoscopic endonasal transsphenoidal approach and Group [B] for microscopic transsphenoidal approach.

\section{Preoperative evaluation}

All patients were subjected to preoperative assessment which includes: history taking, systemic and neurological examination, visual, rhinological, endocrine and radiological assessment. The pituitary tumors were classified according to their invasiveness using Hardy classification system into grades and stages.

\section{Operative approaches}

The approaches were achieved through the nasal, sphenoid, sellar, and sellar reconstruction phases. The used endoscope is [1D Karl Storz, Tuttlingen, Germany] a rigid scope $4 \mathrm{~mm}$ diameter, $30 \mathrm{~cm}$ in length, and with 0 degree and 30-degree, according to the different steps of the surgical operation. The used microscope was [MOLLER Hi- R 1000]

\section{Postoperative assessment}

All patients were assessed immediately for neurological condition, vital signs and all data were recorded. The patients were monitored for nasal or post nasal CSF leak after removal of the packs. Postoperative ophthalmologic conditions including, visual acuity, fundus examination and visual field were assessed. Cases with intra-operative CSF leak, insertion of temporary lumbar drain was done. A protocol for monitoring fluid balance, electrolytes imbalance, and blood sugar were checked every 24 hours and managed. CT in a case of severe headache, sudden deterioration of vision, or deterioration of the conscious level.

\section{Fellow up}

All patients were followed up and examined by an attending neurosurgeon, otolaryngologist and endocrinologist one month after surgery, 3 months, and then yearly thereafter. Hormonal outcome was the lowest post-operative values documented after long term follow up. Radiological outcome was MRI done three months post-operatively in uncomplicated cases, and it was classified into, total [no radiological evidence of residual tumor], subtotal [less than $20 \%$ tumor residual], partial [tumor residual 20\%- 50\%], and insufficient removal [more 
than $50 \%$ residual]. Visual and clinical outcome was categorized into improved, stationary, and worse. The outcome was verified through a summation of clinical, hormonal, and radiological finding. Complementary treatment; Gama Knife and radiation therapy had been used for cases with cavernous sinus residual.

\section{Ethical considerations}

The research was approved by the Institution Research Board [IRB] of Damietta faculty of medicine, Al-Azhar University. Informed verbal consent was obtained from each participant in the study.

\section{Statistical analysis}

Data was fed to the computer and analysed using IBM, SPSS software package version 20.0. [Armonk, NY: IBM Corp]. Qualitative data were described using number and percentage. The Kolmogorov- Smirnov test was used to verify the normality of distribution. Quantitative data were described using range [minimum and maximum], mean, and standard deviation, median and interquartile range $[I Q R]$. Significance of the obtained results was judged at the $5 \%$ level.

\section{RESULTS}

The age was ranging from [17-67] years, with the mean age was 36.4 years. Male patients were 18 cases [60\%] while female patients were 12 cases [40\%]. Visual manifestation was the commonest presenting symptom [70\%] of patients in both endoscopic and microscopic groups. Variable degrees of visual field defects were detected in [60\%]. Diminution of visual acuity was reported in both endoscopic and microscopic groups $[53.3 \%$ \& $66.7 \%]$, blindness due to apoplexy $[6.7 \%$ \& $13.3 \%]$ respectively and third cranial nerves affection [6.7\%] in both groups. While headache [36.7\%] was reported in both endoscopic and microscopic groups [40\% \& 33.3\%] respectively.

All cases of pituitary tumors patients were macroadenomas with stage B [60\%] in both groups. Including all the procedures elsewhere, 33 surgical operative procedures were performed for 30 patients fifteen endoscopic transsphenoidal resection of pituitary tumors were performed and fifteen endonasal microscopic transsphenoidal surgeries were performed, one case with persistent post-operative CSF leak were operated endoscopically for repair of the sellar floor [one patient from group B]. One patient of group B developed sphenoid sinus infection and abscess formation, re-operated for evacuation of the abscess by transnasal transsphenoidal approach, and finally another patient had second re-operation through transcranial approach, [one patient from group B] due to difficult tumor resection through the transsphenoidal approach due to tumor fibrosis.

Operative time was ranged from $80.0-150.0$ min [mean $108.0 \mathrm{~min}$ ] in group $A$ and from $60.0-150.0$ min [mean $88.0 \mathrm{~min}$ ] in group $\mathrm{B}$. This difference in operative time was found to be statistically significant.

The commonest intra-operative complications were CSF leakage in 3 cases [ 1 patients group A and 2 patients group B]. Difficult tumor resection due to tumor fibrosis had occurred in one case [one case in group B]. Intra-operative CSF leakage occurred in one [6.7\%] case of Stage $E$ tumor [one patients group A], while occurred in 2 [13.3\%] cases in Group B one case Stage B, one case Stage C.

Postoperatively, one patient [Group B] had CSF leakage in early postoperative period among three patients who had experienced CSF leakage intra-operatively that mandated temporary lumbar drain and sellar floor repair because conservative management with good intraoperative sellar repair and fat graft succeeded to stop the leak in two patients. Diabetes insipidus had presented in 3 cases, one [6.7\%] patient in Group A and 2 [13.3\%] patients in Group B. One [6.7\%] patients had postoperative sinusitis and abscess formation in sphenoid sinus [one case group B]. Two cases of anosmia were reported one in each group.

The length of hospital stay duration for group A ranged from 3 to 6 days [mean 3.4 days, SD 0.91] while in group $B$, it ranged from 3 to 7 days [mean 4 days, SD 1.36].

In group A, visual field improved in 9 patients [90\%] and stationary in 1 cases [10\%], visual acuity improved in 7 cases [87.5\%] and remains stationary in one case [12.5\%], blindness improved in the case with pituitary apoplexy. In group B: visual field improved in 8 cases [72.7\%] and 3 cases [27.3] showed post-operative stationary course, visual acuity improved in 8 cases [80\%] and remains stationary in 2 cases [20\%]. Blindness after apoplexy improved in one case and remains stationary in one case.

Complete tumor resection achieved in 13 patients [86.7\%] in group A compared to 10 patients [66.7\%] in group $B$, subtotal tumor resection in 2 patients [13.3\%] in group $A$, while it was achieved in 3 patients [20\%] in group $\mathrm{B}$, and partial resection was achieved in one patients $[6.7 \%]$ in group $B$, while insufficient removal was achieved in one patients $[6.7 \%]$ in group $B$.

Case presentations are shown in figures [1-4]. 

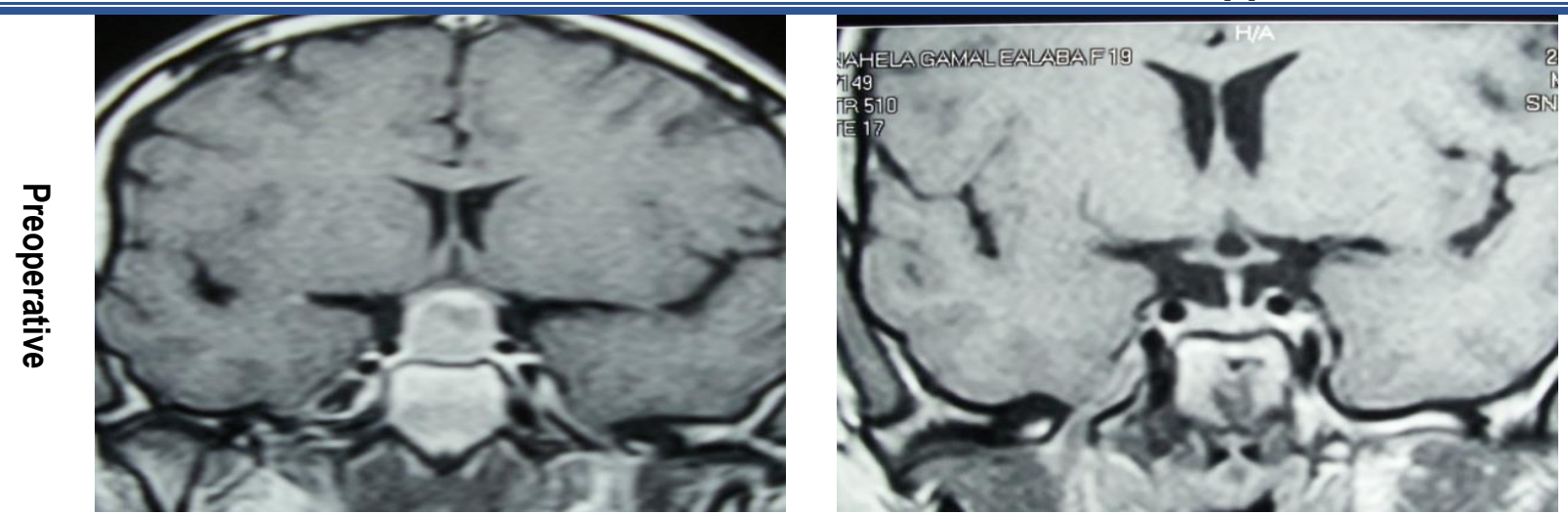

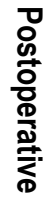

Figure [1]: Case 1: 24 years old female with accidently discovered nonfunctioning pituitary adenoma. She was operated upon by endoscopic endonasal approach. Tumor was totally removed.
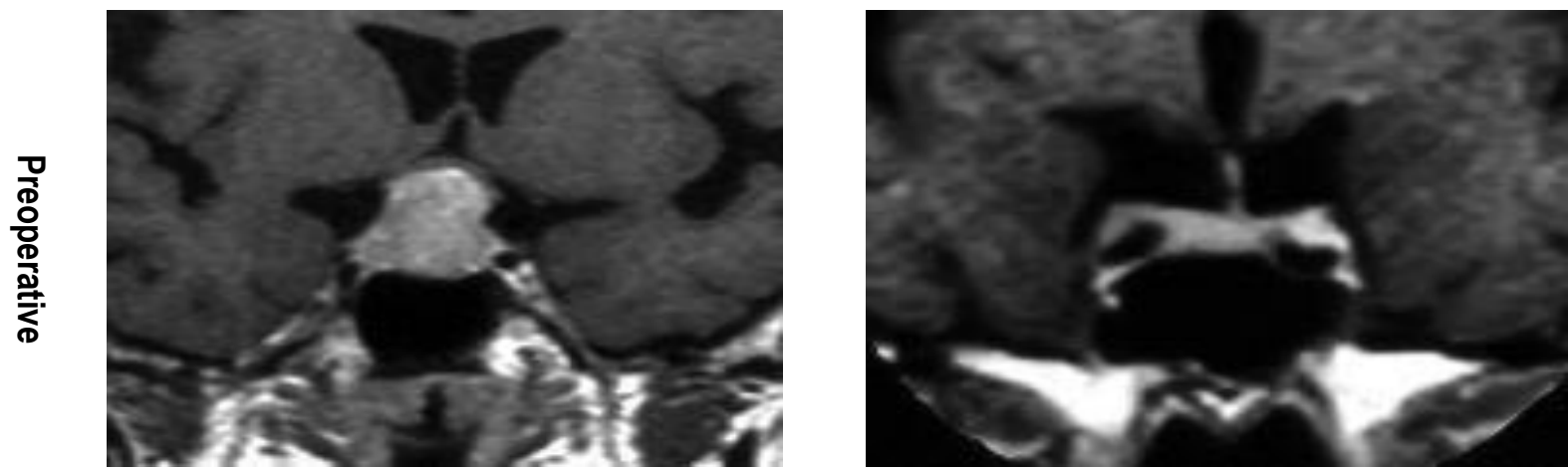

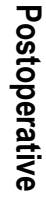

Figure [2]: Case 2: 25 years old male was complaining of progressive diminution of vision. All the hormonal profiles were normal. He was operated upon by endoscopic endonasal approach. Tumor was totally removed
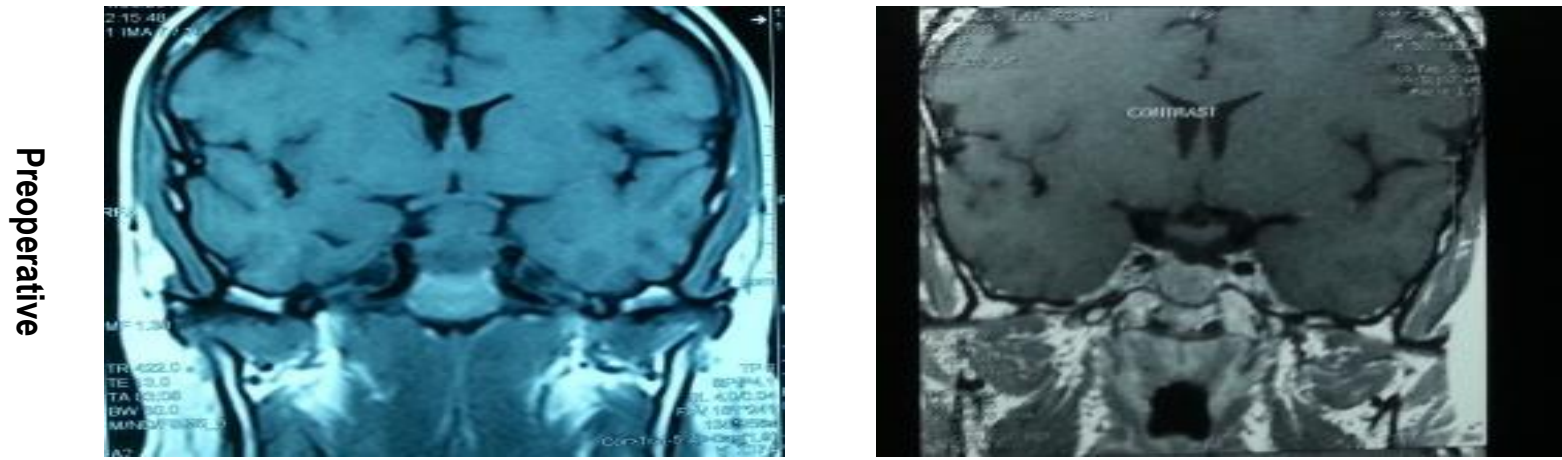

Figure [3]: Case 3: 34 years old male complaining of gradual progressive diminution of vision was operated upon by microscopic endonasal approach. Tumor was totally removed and the patient's vision improved.
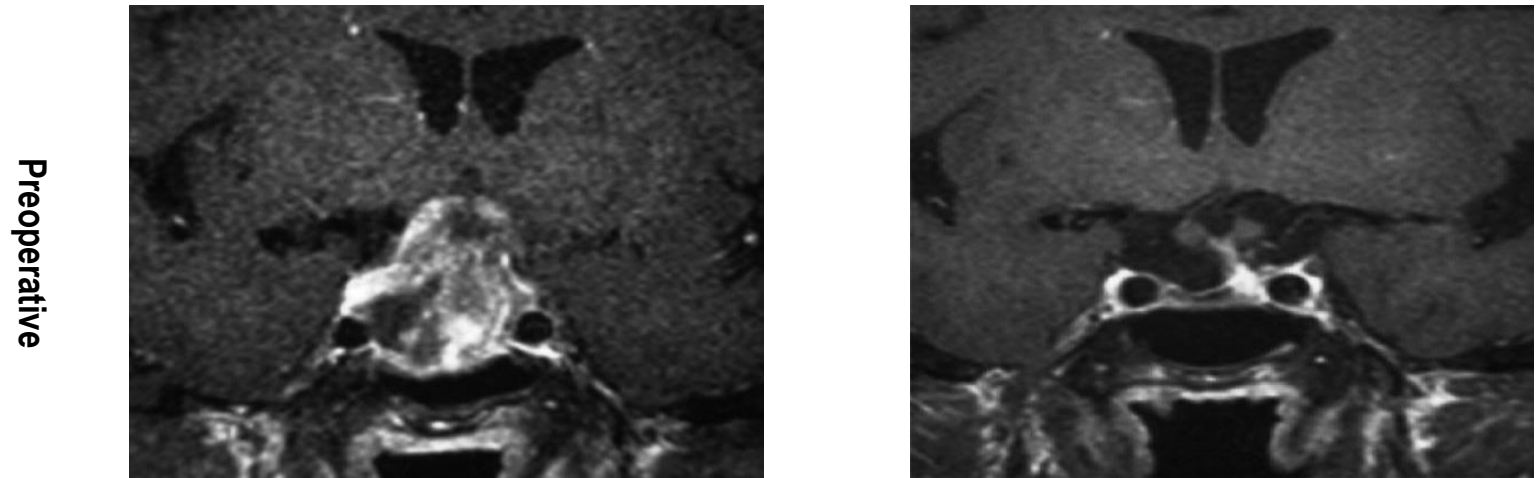

Figure [4]: Case 4: 31 years old male was complaining of headache and progressive diminution of vision. All the hormonal profiles were normal. Patient was operated upon by microscopic endonasal approach. Tumor was totally removed. 


\section{DISCUSSION}

The goals of endonasal transsphenoidal surgery in nonfunctioning pituitary adenomas include decompression of the optic apparatus, regain normal pituitary gland and stalk. Therefore outcomes can be measured using a combination of imaging, and clinical parameters.

In our study, we observed that the male patients were predominant $[60 \%]$ than females, and the mean age was [36.4] year old, approximating what reported by Al-Shami et al. [4] while Cesák et al. [5] reported a higher mean age [59.6 years] for microscopic group and [58.7 year] for endoscopic group with predominant male patients.

In our study, we reported [60\%] of the pituitary macroadenomas is stage B in both groups, which were coincident with Dallapiazza et al. ${ }^{[6]}$.

In our study, we reported a better recovery as regard visual field and visual acuity in endoscopic group [90\%] than microscopic group [72.7\%]. However, we didn't observe any postoperative visual deterioration in contrast to Dallapiazza et al. [6], as they achieved [39\%] recovery of visual defects in endoscopic cases; however, Cesák et al. [5] reported better results in the form of [96\%] improvement in patients with preoperative visual deficits. This might be explained by residual tumors, longstanding preoperative optic apparatus compression in our study.

We reported a higher percentage of gross total removal [GTR] in the endoscopic group [86.7\%] than in microscopic group [66.7\%]. These results were in agreement with Little et al. ${ }^{[7]}$ who reported $83.7 \%$ gross total removal rates in endoscopic group. Our results were also in line with Kassis et al. ${ }^{[8]}$ who reported GTR rates as $86.1 \%$ in endoscopic group versus $65.5 \%$ in microscopic group, respectively. Messerer et al. [9] reported GTR in $50 \%$ of microscopic group and $74 \%$ in endoscopic group, while Karppinen et al. [10] reported $56 \%$ and $45 \%$ GTR in endoscopic and microscopic groups respectively. However, Cesák et al. [5] observed $72 \%$ GTR in endoscopic group and $80 \%$ in microscopic group. The improved results with endoscopic group are best explained by the increased parasellar and suprasellar tumor propagation. Sabry et al. [11] reported that volume reduction in the microscopic group had a mean of $82.4 \%$ which was not significantly different from the endoscopic group volume reduction [89.1\%]

We reported 20\% intraoperative bleeding in endoscopic versus $6.7 \%$ in microscopic procedure. However, postoperative anosmia reported equally in both groups and postoperative sinusitis with abscess formation reported in one patient of the microscopic group. Cesák et al. [5] reported that rhino-logical complications [bleeding, inflammation] were noted in fewer than $8 \%$ in both groups. Agam et al. [12] reported $1.1 \%$ of postoperative epistaxis of patients with both endoscopic and microscopic approaches.

The intra-operative CSF leak was slightly higher in the microscopic [13.3\%] than endoscopic procedure [6.7\%]. Jane Jr. et al. [13] reported that $30 \%$ of their patients had intraoperative CSF leak. One of them [5.5\%] experienced require surgical repair of the sellar floor.

Our results showed a trend over time toward a reduced percentage of total complications for patients undergoing endoscopic resection due to improvement of learning curve. However, Agam et al. ${ }^{[12]}$ reported that CSF leak was slightly higher for the endoscopic group [3.5\%] versus [2.4\%] in microscopic group with decreasing CSF leak as learning curve becomes better. Sabry et al. [11] reported higher incidence of CSF leak up to $40 \%$ in microscopic group and $15.2 \%$ in endoscopic group. Cesák et al. [5] reported higher incidence in the endoscopic cases $[10.67 \%]$ versus [3\%] in the microscopic ones.

In our study, we did not report any case of meningitis. However, Pablo et al. [14] reported meningitis in $2.7 \%$ of patients in microscopic group and $2.1 \%$ in endoscopic group. Dallapiazza et al. ${ }^{[6]}$ reported meningitis in $1 \%$ of patients in whom CSF leak was persistent. Skulsampaopol and Hansasuta [15] reported meningitis in [3\%], one of the three ensued from postoperative CSF leakage, whereas the other two patients did not have postoperative leakage.

In our study, we reported postoperative diabetes insipidus [DI] in $6.7 \%$ equally in both groups. Cesák et al. [5] experienced a higher percentage of $\mathrm{DI}$ in both groups [14\%], which is not consistent with our data, may be due to different numbers of cases.

In the current study, the microscopic group had longer mean duration of hospital stay [7 days], compared to 6 days for the endoscopic group. This matches the significantly shorter hospital stay for endoscopic resection of non-functioning pituitary adenoma [NFPA] in multiple studies including Sabry et al. ${ }^{[11]}$ and Higgins et al. ${ }^{[16]}$

\section{CONCLUSION}

We conclude that, the direct endonasal transsphenoidal approach with either endoscopic or microscopic is a safe and effective method to remove nonfunctioning pituitary adenomas associated with a rapid rhinological recovery and a low occurrence of serious long term sinonasal complaints. The endoscopic endonasal approach provides 
more complete tumor removal, less postoperative pain, shorter hospitalization, fewer postoperative complications. Improvement of the learning curve of endoscopic endonasal approach allows it to become the gold standard for pituitary adenomas in the future.

\section{Financial and Non-financial Relationships and Activities of Interest}

None

\section{REFERENCES}

1. Inoshita N, Nishioka H. The 2017 WHO classification of pituitary adenoma: overview and comments. Brain Tumor Pathol. 2018 Apr;35[2]:51-56. DOI: 10.1007/ s10014-0180314-3.

2. Liu YQ, Gao BB, Dong B, Padikkalakandy Cheriyath SS, Song $\mathrm{QW}, \mathrm{Xu} \mathrm{B}$, et al. Preoperative vascular heterogeneity and aggressiveness assessment of pituitary macroadenoma based on dynamic contrast-enhanced MRI texture analysis. Eur J Radiol. 2020 Aug; 129:109125. DOl: 10.1016/j.ejrad.2020.109125.

3. Nishioka H. Recent Evolution of Endoscopic Endonasal Surgery for Treatment of Pituitary Adenomas. Neurol Med Chir [Tokyo]. 2017 Apr 15;57[4]:151-158. DOI: 10.2176/nmc.ra.2016-0276.

4. Al-Shami $H$, Alnemare AK, Bin Mahfoz $T$, Salah AM. Endoscopic versus microscopic pituitary adenoma: comparative study of two different approaches. Med. J. Cairo Univ. 2020 December; 88 [5]: 2367-73. DOl: 10.21608/mjcu.2020.125471

5. Česák T, Póczoš P, Adamkov J, Čelakovský P, Gabalec F, Soukup J, Dvořáková R, Krůpa $P$. Microsurgical versus endoscopic surgery for non-functioning pituitary adenomas: a retrospective study. Croat Med J. 2020 Oct 31;61[5]:410-421. DOI: $10.3325 / \mathrm{cmj} .2020 .61 .410$.

6. Dallapiazza RF, Grober Y, Starke RM, Laws ER Jr, Jane JA Jr. Long-term results of endonasal endoscopic transsphenoidal resection of nonfunctioning pituitary macroadenomas. Neurosurgery. 2015 Jan;76[1]:42-52. DOI: 10.1227/NEU.0000000000000563.

7. Little AS, Kelly DF, White WL, Gardner PA, FernandezMiranda JC, Chicoine MR, et al. Results of a prospective multicenter controlled study comparing surgical outcomes of microscopic versus fully endoscopic transsphenoidal surgery for nonfunctioning pituitary adenomas: the Transsphenoidal Extent of Resection [TRANSSPHER] Study. J Neurosurg. 2019; 132[4]:1043-1053. DOI: 10.3171/2018.11.JNS181238.
8. Kassis S, De Battista JC, Raverot G, Jacob M, Simon E, Rabilloud M, et al. [Endoscopy versus microsurgery: results in a consecutive series of nonfunctioning pituitary adenomas]. Neurochirurgie. 2009;55[6]:607-15. DOI: 10.1016/j.neuchi.2009.05.003.

9. Messerer M, De Battista JC, Raverot G, Kassis S, Dubourg J, Lapras V, et al. Evidence of improved surgical outcome following endoscopy for nonfunctioning pituitary adenoma removal. Neurosurg Focus. 2011 Apr;30[4]:E11. DOI: 10.3171/2011.1. FOCUS10308.

10. Karppinen A, Kivipelto L, Vehkavaara S, Ritvonen E, Tikkanen E, Kivisaari R, et al. Transition from Microscopic to Endoscopic Transsphenoidal Surgery for Nonfunctional Pituitary Adenomas. World Neurosurg. 2015;84[1]:48-57. DOI: 10.1016/j.wneu.2015.02.024.

11. Sabry HA, Elayouty AED, Mashaly HA, Elsherbiny AA, Yasin A. Surgical outcome of non-functioning pituitary adenomas: a comparative study between microscopic and endoscopic techniques. Egypt J Neurosurg. 2018; [33]:18. DOl: 10.1186/s41984-018-0019-2

12. Agam MS, Wedemeyer MA, Wrobel B, Weiss $M H$ Carmichael JD, Zada G. Complications associated with microscopic and endoscopic transsphenoidal pituitary surgery: experience of 1153 consecutive cases treated at a single tertiary care pituitary center. J Neurosurg. 2018 Jun 1:1-8. DOI: 10.3171/2017.12. JNS172318.

13. Jane JA Jr, Starke RM, Elzoghby MA, Reames DL, Payne SC, Thorner MO, et al. Endoscopic transsphenoidal surgery for acromegaly: remission using modern criteria, complications, and predictors of outcome. J Clin Endocrinol Metab. 2011;96[9]:2732-40. DOI: 10.1210/jc.2011-0554.

14. Pablo A, Sofia B, Maximiliano T, Patricia FD, Alvaro C, Claudio Y, Antonio C. Endoscopic versus Microscopic Pituitary Adenoma Surgery: A Single-center Study. Neurol India. 2019 Jul-Aug;67[4]:1015-1021. DOI: 10.4103/00283886.266241 .

15. Skulsampaopol J, Hansasuta A. Outcomes of the Endoscopic Transsphenoidal Surgery for Resection of Pituitary Adenomas Utilizing Extracapsular Dissection Technique with a Cotton Swab. Asian J Neurosurg. 2019;14[4]:1089-94. DOI: 10.4103/ajns.AJNS_169_19.

16. Higgins TS, Courtemanche C, Karakla D, Strasnick B, Singh RV, Koen JL, Han JK. Analysis of transnasal endoscopic versus transseptal microscopic approach for excision of pituitary tumors. Am J Rhinol. 2008 Nov-Dec;22[6]:649-52. DOI: 10.2500/ajr.2008.22.3246. 


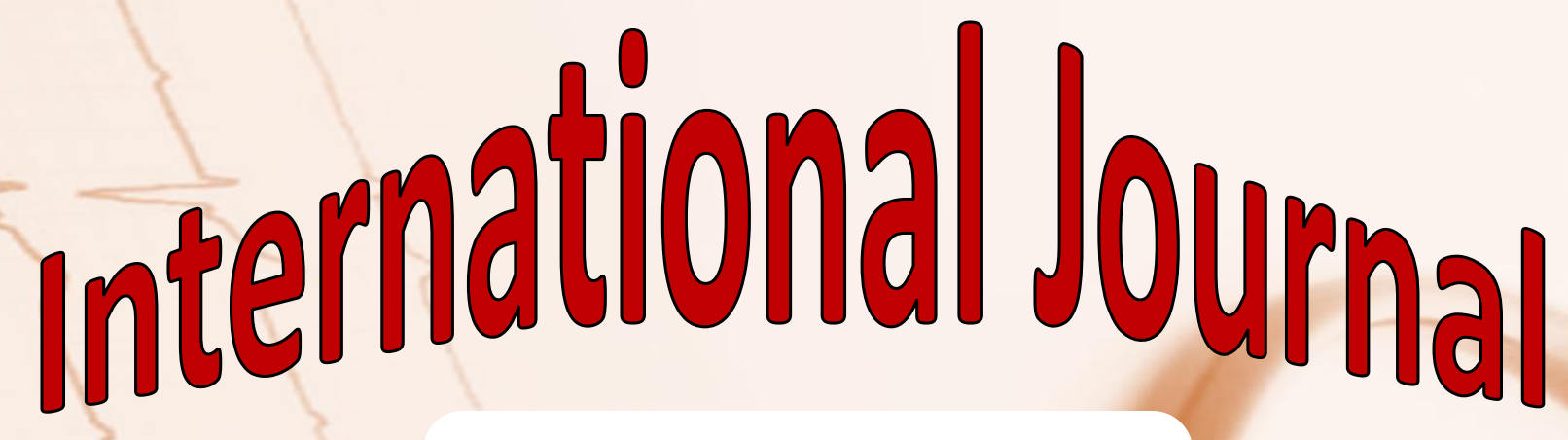

https://ijma.journals.ekb.eg/ Print ISSN: 2636-4174 Online ISSN: 2682-3780

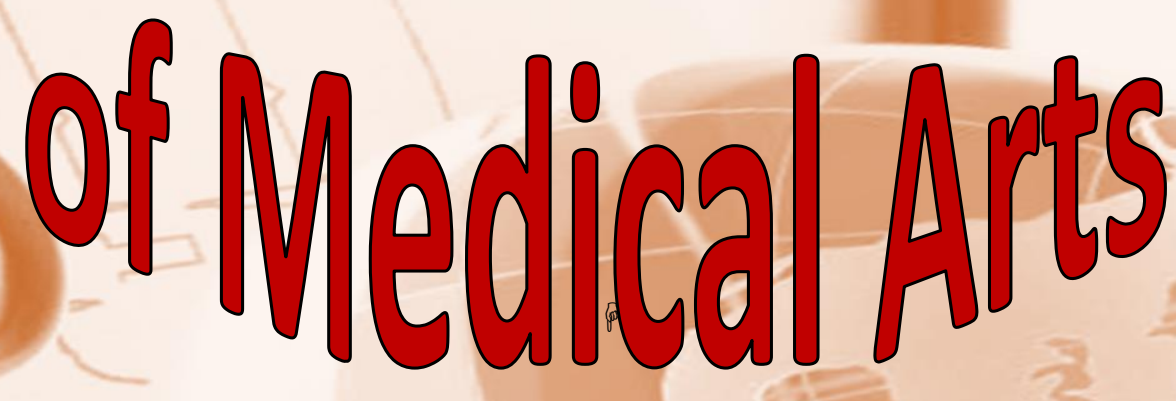

